\title{
The true depth of the Mediterranean plastic problem: Extreme microplastic pollution on marine turtle nesting beaches in Cyprus
} \author{
Brendan J. Godley ${ }^{\mathrm{a}, *, 3}$ \\ ${ }^{a}$ Marine Turtle Research Group, Centre for Ecology and Conservation, University of Exeter, Penryn, Cornwall, UK \\ ${ }^{\mathrm{b}}$ Marine Ecology and Biodiversity, Plymouth Marine Laboratory, Prospect Place, West Hoe, Plymouth, UK \\ ${ }^{c}$ Society for Protection of Turtles, PK 42, Mersin 10, Turkey \\ ${ }^{\mathrm{d}}$ Institute for Marine and Atmospheric Research, Utrecht University, Utrecht, Netherlands
}

Emily M. Duncan ${ }^{\mathrm{a}, \mathrm{b}, 1}$, Jessica Arrowsmith ${ }^{\mathrm{a}, 1}$, Charlotte Bain ${ }^{\mathrm{a}, 1}$, Annette C. Broderick ${ }^{\mathrm{a}}$, Jonathon Lee $^{\mathrm{a}}$, Kristian Metcalfe ${ }^{\mathrm{a}}$, Stephen K. Pikesley ${ }^{\mathrm{a}}$, Robin T.E. Snape ${ }^{\mathrm{a}, \mathrm{c}}$, Erik van Sebille ${ }^{\mathrm{d}, *, 2}$,

\section{A R T I C L E I N F O}

\section{Keywords:}

Plastic

Marine turtles

Nesting beach

Oceanographic models

\begin{abstract}
A B S T R A C T
We sampled 17 nesting sites for loggerhead (Caretta caretta) and green turtles (Chelonia mydas) in Cyprus. Microplastics ( $<5 \mathrm{~mm}$ ) were found at all locations and depths, with particularly high abundance in superficial

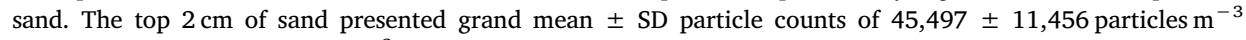
(range 637-131,939 particles $\mathrm{m}^{-3}$ ). The most polluted beaches were among the worst thus far recorded, presenting levels approaching those previously recorded in Guangdong, South China. Microplastics decreased with increasing sand depth but were present down to turtle nest depths of $60 \mathrm{~cm}$ (mean 5,325 $\pm 3,663$ particles $\mathrm{m}^{-3}$. Composition varied among beaches but hard fragments $(46.5 \pm 3.5 \%)$ and pre-production nurdles $(47.8 \pm 4.5 \%)$ comprised most categorised pieces. Particle drifter analysis hindcast for 365 days indicated that most plastic likely originated from the eastern Mediterranean basin. Worsening microplastic abundance could result in anthropogenically altered life history parameters such as hatching success and sex ratios in marine turtles.
\end{abstract}

\section{Introduction}

\subsection{Plastic in the marine environment}

Plastic is now ubiquitous in the marine environment and accounts for $86 \%$ of all anthropogenic marine debris globally (Laist, 1987; Barnes et al., 2009; Ivar Do Sul and Costa, 2014; Jambeck et al., 2015; Nelms et al., 2017). Its mobility and high concentrations allow it to interact with a wide variety of marine biota through multiple pathways, and so plastic is considered a growing threat to marine biodiversity (Derraik, 2002; Cole et al., 2013; Gall and Thompson, 2015; Nelms et al., 2016). The dispersion of plastic across oceans facilitates the rafting of invasive species, plastic entanglement and ingestion, causing injury and death (Derraik, 2002; Gall and Thompson, 2015; Nelms et al., 2016; Duncan et al., 2017).

\subsection{Microplastics}

By definition, microplastics ( $<5 \mathrm{~mm}$ ) (Andrady, 2011) can enter the marine environment from primary sources via industrial spills as pre-production nurdles, through runoff from sewage systems, as microbeads from cosmetics, and as microfibers from clothes or tyre wear (Moreira et al., 2016; Nelms et al., 2017; Gago et al., 2018). Microplastics can also be created secondarily through fragmentation, whereby discarded macroplastics $(\geq 5 \mathrm{~mm}$ ) breakdown through UV exposure and mechanical abrasion, such as wave action and weathering (Hopewell et al., 2009; Andrady, 2011). As fragmentation continues particle size reduces; for example the mean length of plastic in the North Atlantic reduced from $10 \mathrm{~mm}$ to $5 \mathrm{~mm}$ between 1991 and 2017 (Morét-Ferguson et al., 2010).

The scale of the problem mandates a focus on the biological impacts of microplastics (Ivar Do Sul and Costa, 2014; Vegter et al., 2014;

\footnotetext{
* Corresponding authors.

E-mail addresses: e.vansebille@uu.nl (E. van Sebille), b.j.godley@exeter.ac.uk (B.J. Godley).

${ }^{1}$ All authors contributed equally.

${ }^{2}$ Corresponding author regarding particle drifter analysis.

${ }^{3}$ Corresponding author regarding field data and analysis.
} 
Nelms et al., 2016). This includes assessing their ability to be passed up the food chain through trophic transfer (Fossi et al., 2012; Cole et al., 2013; Van Cauwenberghe et al., 2015). Additionally, the affinity of plastics with PCBs and other toxic chemicals, enables microplastics to be a potential vector for the trophic transfer of toxins (Ryan et al., 1988; Tanaka et al., 2012; Storelli and Zizzo, 2014).

\subsection{Microplastics \& beach sediments}

Microplastic abundance on beaches is thought to have tripled over the last twenty years (Moore, 2008; Ivar Do Sul and Costa, 2014). Microplastics wash onto beaches from surface waters and become incorporated within the sediment as beach volumes alter through erosion and accretion events (Thom and Hall, 1991; Barnes et al., 2009; Poeta et al., 2014). In contrast with natural sediments, microplastics are more angular, resulting in unpredictable patterns of weathering (Cooper and Corcoran, 2010). These atypical properties have been shown to have the potential to increase sediment permeability and porosity, and decrease substrate temperatures (Carson et al., 2011). However other studies consider that temperatures would increase as plastics have a higher specific heat capacity than sand, especially if the pigment of the plastic is dark (Andrady, 2011; Beckwith and Fuentes, 2018). Marine turtle nesting success is strongly influenced by extrinsic factors during egg development (McGehee, 1990; Ackerman, 2002; Warner, 2014). In particular, temperature influences the duration and success of development and determines the sex of offspring (Ackerman, 2002; Horne et al., 2014; Hays et al., 2017). High microplastic abundance within sand in turtle nests could impact hatching success and skew hatchling sex ratios (Cooper and Corcoran, 2010; Nelms et al., 2016).

\subsection{Microplastics \& Mediterranean marine turtles}

Northern Cyprus hosts some of the most important nesting beaches in the Mediterranean for both loggerhead (Caretta caretta) and green turtles (Chelonia mydas) (Kasparek et al., 2001; Broderick et al., 2002; Stokes et al., 2015). The Mediterranean basin is associated with dense coastal populations with high levels of anthropogenic waste and variable governance levels (Coll et al., 2010), consequently the Mediterranean has been found to hold plastic concentrations comparable to the largest congregations of plastic on the globe such as in the North Pacific gyre e.g. $>10^{5}$ particles $\mathrm{km}^{-2}$ (Cózar et al., 2014, 2015; van Sebille et al., 2015). This study aimed to: 1) quantify the composition, distribution, abundance and spatial variation of microplastics across beaches in Cyprus 2) look at how this varied at depth in the sediment and 3) use oceanographic current models to identify the potential source locations of the plastic.

\section{Materials \& methods}

\subsection{Study area}

Sampling was carried out at 17 beaches along the coastline of Cyprus in the Eastern Mediterranean between July and August 2016 (Fig. 1; Supplemental Table 1). Surveys were coincided with the main period of turtle nesting/hatching activity. Beaches were selected, based upon their spatial distribution and high turtle nesting densities (Broderick et al., 2002).

\subsection{Sediment sampling}

Within each beach, sediment samples were collected from 10 pairs of sampling sites along two lines parallel to the shore: the "strandline" (SL) and the "turtle nesting line" (TNL). The 10 sampling sites were spaced equidistantly along the beach length, avoiding rocky edges of the beach (Supplemental material Fig. 1). Co-ordinates were taken at all sample locations (longitude/latitude: World Geodetic System (WGS)

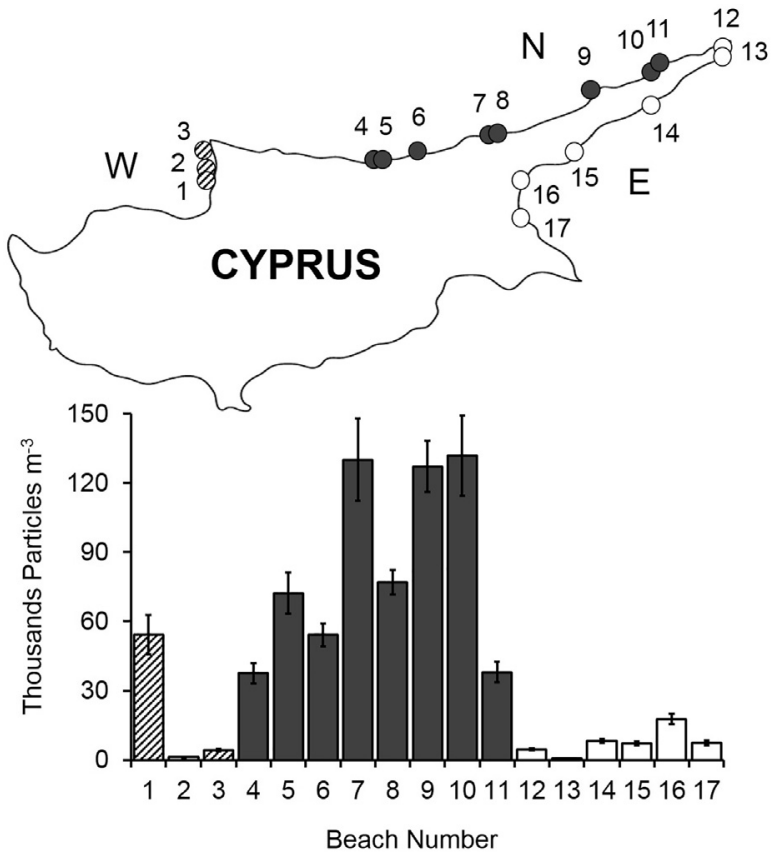

Fig. 1. Mean microplastic in particles $\mathrm{m}^{-3}$ within turtle nesting line (TNL) surface samples $(0-2 \mathrm{~cm})$, across numbered sample beaches with fitted standard error bars. Stack shades represent the three different coastlines in the map insert: Hatched $=$ West $(n=3$, beach number $1-3)$, Grey $=$ North $(n=8$, beach number 4-11), White $=$ East $(n=6$, beach number 12-17). Individual beach co-ordinates can be found in Table 1 , supplementary data.

1984 format) using a Garmin eTrex ${ }^{\circledR} 10$ handheld GPS device. (Supplemental Table 1.) Strandline (SL) was defined as the highest line of debris left from the retreating tide. This meandering line where debris accumulates is periodically generated by tide, wave and air movements (Heo et al., 2013). The turtle nesting line (TNL) was a transect through typical turtle nesting area. This was approximately the medial distance between strandline and the landward limit of the beach within which turtles nested, approximated by a) marked nests recorded as part of exhaustive ongoing monitoring, b) body pits left from nesting attempts (Broderick and Godley, 1996).

All samples were collected using a bespoke cylindrical galvanised steel corer of $20 \mathrm{~cm}$ diameter and $60 \mathrm{~cm}$ height. A volume of $250 \mathrm{~cm}^{3}$ was gathered for $0-2 \mathrm{~cm}$ depth at sampling locations on the strandline (SL) to allow for comparisons with recent similar studies (e.g. CluniesRoss et al., 2016; Yu et al., 2016; Zhang et al., 2016). At the turtle nesting line (TNL) a volume of $250 \mathrm{~cm}^{3}$ was taken from incremental depths (0-2.0, 2.1-10.0, 10.1-20.0, 20.1-30.0, 30.1-40.0, 40.1-50.0, $50.1-60.0 \mathrm{~cm}$ ). Due to striking water or rock it was not always possible to core to the full $60 \mathrm{~cm}$. Samples were air dried in metal trays covered in aluminium foil to avoid loss and/or contamination of microplastics from other environmental sources prior to processing.

\subsection{Separation and categorisation}

Dry weight of whole sediment subsamples was measured to an accuracy of $0.01 \mathrm{~g}$, before being passed through a sieve cascade of $5 \mathrm{~mm}$ and $1 \mathrm{~mm}$ to capture microplastics $(<5 \mathrm{~mm}$ and $>1 \mathrm{~mm}$ (Andrady, 2011). Anthropogenic debris was then isolated from each sample and categorised based on procedures proposed by van Franeker et al. (2011).

\subsection{Plastic categories}

Plastics were then assigned to one of five categories (van Franeker et al., 2011): (1) Industrial (IND) - Roughly spherical plastic pellets 
used in industrial practice as primary pre-production material to melt and mould (known as: nurdles, pellets, beads, granules); (2) Foamed (FOAM) - Synthetic sponge, mattress foam, polystyrene, polyurethane; (3) Fragment (FRAG) - Broken down pieces of hard plastic from bottles and other consumer items; (4) Sheet-like (SHE) - remains of sheeting and bags; and (5) Thread-like (THR) - remains of netting, ropes, net packaging, nylon fishing line. Microplastic debris from each category within each sample was counted and weighed to $0.0001 \mathrm{~g}$. With these data, dry weights and known volume data were converted into four different units for analysis and comparison with the wider literature: particles $\mathrm{m}^{-3}$, particles $\mathrm{g}^{-1}, \mathrm{~g} \mathrm{~m}^{-3}$ and $\mathrm{gg}^{-1}$.

\subsection{Particle drifter analysis}

To investigate the potential source and at-sea trajectories of floating, passive plastic we used the Parcels framework (Lange and van Sebille, 2017) to model backward trajectory probabilities for virtual particles released from seventeen beaches (Supplemental Table 2.). Using established methodologies from Lagrangian Ocean Analysis (van Sebille et al., 2018), the virtual particles were transported by the flow from hydrodynamic circulation models. Hydrodynamic data were sourced from the HYbrid Coordinate Ocean Model (HYCOM: hycom. org) + NCODA Global Reanalysis at 1/12 degree resolution and daily output frequency (Cummings and Smedstad, 2013). One particle was released from each beach for every day from 5 July 2015 to 1 July 2016 with each particle being advected (back in time) for 365 days. The timestep of the 4th order Runge-Kutta integration was $5 \mathrm{~min}$ and particle locations were saved at daily frequency. Due to spatial limitations within the HYCOM gridded data, start locations for back-tracked drifter simulations from beaches 15, 16 and 17 (Fig. 1.) were relocated 0.06 degrees east (approx. $5 \mathrm{~km}$ ) to enable flow to be simulated around these release sites. The python code for these simulations is available at https://github.com/OceanParcels/Plastic_CyprusBeaches/.

For each beach release location, a sampling grid of $20 \times 20 \mathrm{~km}$ grid squares was used to sum all spatially coincident daily drifter trajectory locations. The same sampling grid was used to determine the number of individual drifter trajectories traversing a grid square. To enable 'at sea' trajectories to be clearly displayed, trajectory location data within $5 \mathrm{~km}$ of the coast were removed from the analysis. Where back-tracked particle trajectories terminated at coastal locations (particles became stationary and were no longer advected) these were deemed to be the source location for the trajectory and were summarised by country.

\section{Results}

\subsection{Overview}

A total of 1209 sediment samples were obtained from 170 turtle nesting area samples and 170 strandline sampling locations across the 17 nesting beaches. Microplasticswere found to be pervasive in all sampled locations and depths, with particularly high abundance within the top $2 \mathrm{~cm}$ of sand. The grand mean of microplastics in surface samples in the TNL (turtle nesting line) was 45,497 $\pm 11,456$ (mean \pm se) particles $\mathrm{m}^{-3}$ (range across 17 beaches: 637-131,939 particles $\mathrm{m}^{-3}$ ) and a grand mean weight of $481 \pm 131 \mathrm{~g} \mathrm{~m}^{-3}$ (range across beaches: $1-1714 \mathrm{~g} \mathrm{~m}^{-3}$ ). There was no significant difference between mean values on the strandline and the turtle nesting line (Paired $t$-test: particles $\mathrm{m}^{-3} \mathrm{t}_{16}=1.14, p=0.28$; $\mathrm{g} \mathrm{m}^{-3}: \mathrm{t}_{16}=0.07, p=0.94$; Supplemental Table 1).

\subsection{Beach variation}

Abundance of microplastics in the turtle nesting line was found to vary significantly across beaches in both particles (particles $\mathrm{m}^{-3}$; ANOVA, $\left.\mathrm{F}_{2,14}=12.32, p<0.001\right)$ and mass $\left(\mathrm{g} \mathrm{m}^{-3}\right.$; ANOVA, $\left.\mathrm{F}_{2,14}=13.52, p<0.001\right)$. Coastal position of the beach had a
Microplastic Abundance

Thousands Particles $\mathrm{m}^{-3}$

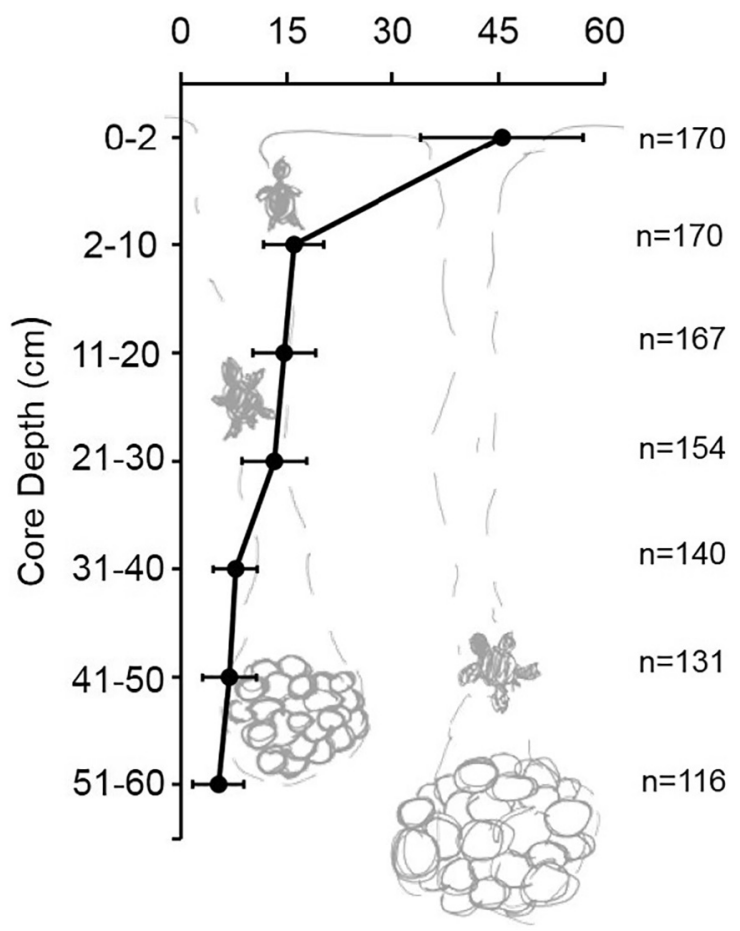

Fig. 2. Grand mean ( \pm S.E) of microplastic abundance in particles $\mathrm{m}^{-3}$ at different sand depths at turtle nesting areas $(n=17$ sites). Nesting depth depicted of loggerhead and green turtles. $\mathrm{n}=$ number of core samples per depth.

significant effect on microplastic abundance (particles $\mathrm{m}^{-3}$ : $\left.\mathrm{F}_{2,14}=11.42, p<0.001 ; \mathrm{g} \mathrm{m}^{-3} \mathrm{~F}_{2,14}=13.97, p<0.001\right)$ with significantly higher levels on the North Coast compared to both the West and East coasts: particles $\mathrm{m}^{-3}$ (Tukey's Honest Significant Difference, North > West: $p<0.001$; North $>$ East: $p<0.001$; West $=$ East: $p=0.95$ ),$\quad \mathrm{g} \mathrm{m}^{-3} \quad$ (Tukey's Honest Significant Difference, North $>$ West: $p=0.01$; North $>$ East: $p<0.001$; West $=$ East: $p=0.97)$. The highest microplastic abundances of $131,939 \pm 34,000$ particles $\mathrm{m}^{-3}$ occurred on Beach 10 (North Coast) (Fig. 1; Supplemental Fig. S2.)

The grand mean maximum depth reached by core samples was $49.5 \pm 1.2 \mathrm{~cm}$ however, maximum depths reached varied considerably by core (range $=8-60 \mathrm{~cm}$ ) with 116 complete cores sampled. Microplastics were found at all depths within sampled beaches, with particles discovered down to $51-60 \mathrm{~cm}$ with mean levels of $5325 \pm 3663$ particles $\mathrm{m}^{-3}$ and $59 \pm 39 \mathrm{~g} \mathrm{~m}^{-3}$ (range: $381-63,344$ particles $\mathrm{m}^{-3} ; 4-638 \mathrm{~g} \mathrm{~m}^{-3}$ ) at that depth. (Fig. 2.Supplemental Fig. S3). This difference among depths was found to be significant for both particles $\mathrm{m}^{-3}$ (Kruskal-Wallis test, $\chi^{2}(6)=28.32, p<0.001$ ) and $\mathrm{g} \mathrm{m}^{-3}$ (Kruskal-Wallis test, $\chi^{2}(6)=23.06, p<0.001$ ); with more microplastics found at shallower levels (Fig. 2. Supplemental Fig. S3). Of the five plastic categories, industrial (IND) and fragment (FRAG) made up $>85 \%$ of microplastic particles present in samples per volume (decreasing in abundance in FRAG $>$ IND $>$ FOAM $>$ SHE $>$ THR) and $98 \%$ by mass (IND $>$ FRAG $>$ SHE $>$ FOAM $>$ THR) (Fig. 3 ).

\subsection{Particle drifter analysis}

Hindcast modelling of at-sea trajectories of plastic revealed that the major source locations occurred almost exclusively in the eastern part of the Mediterranean basin with limited counts from the western section of the basin e.g. Italy, Malta and Tunisia (Fig. 4; Supplemental Fig. 

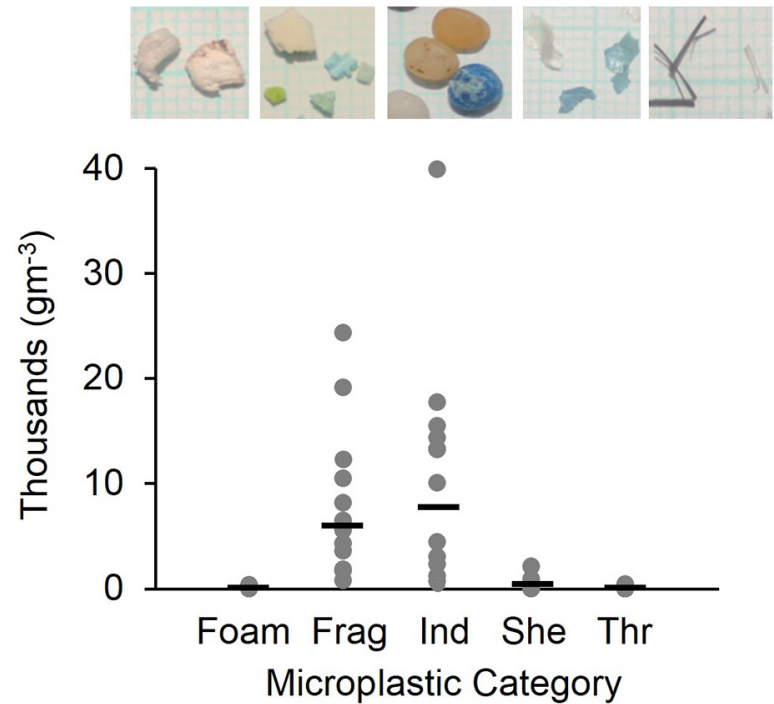

Fig. 3. Microplastic weight/volume $\left(\mathrm{g} \mathrm{m}^{-3}\right)$ classification categories on each beach (grey dots) $(n=17)$. Black line $=$ mean microplastic weight/volume $\left(\mathrm{g} \mathrm{m}^{-3}\right)$ across all sample beaches cores.

S4). There was variability in the count of particles tracked to each drifter source location, with most modelled particles making landfall elsewhere in Cyprus, Turkey and Lebanon and dense particle presence in off-shore accumulation zones (Fig. 5).

\section{Discussion}

\subsection{Microplastics at depth}

The ubiquitous nature of microplastics within nesting beach environments, supports the idea that beaches act as microplastic sinks for the wider oceans (Barnes et al., 2009; Poeta et al., 2014; Nelms et al., 2016) becoming key areas of environmental contamination. Levels in Cyprus were 5-1000 times higher in comparison to other regional studies from Greece, Malta and Spain (Turner and Holmes, 2011; Kaberi et al., 2013; Alomar et al., 2016) and orders of magnitude higher than surface levels on marine turtle nesting beaches in Florida, USA (Beckwith and Fuentes, 2018). Indeed, upon reviewing the literature, the levels of microplastics present on beaches in Cyprus were among the worst thus far recorded, presenting abundances approaching those previously were recorded in Guangdong, South China in 2015 $\left(166,875 \pm 175,525\right.$ particles. $\mathrm{m}^{-3}$; range of means across 8 beaches: 6200-437,625 particles $\mathrm{m}^{-3}$ ) (Fok et al., 2017). Waste input between China and Cyprus however, varies markedly with China producing $27.8 \%$ of global plastic, $50 \%$ more than the whole of (Europe Plastics, 2016), beaches in China are therefore likely to be contaminated from direct, local inputs (Tsang et al., 2017). In contrast many sample beaches in Cyprus are located far from industrial practices with little human usage, therefore likely receiving microplastic via ocean currents from around the eastern Mediterranean (Barnes et al., 2009) Our data are indicative of the generally high plastic levels found within the Mediterranean Sea (Cózar et al., 2015; van Sebille et al., 2015; Alomar et al., 2016).

Microplastics, the vast majority of which are likely to have come via the sea, were ubiquitous upon the beaches of northern Cyprus and were present down to nesting depths of loggerhead and green turtles (Broderick et al., 2002). The ability of significant amounts of small plastic particles to be transferred down through sediments corresponds with the few studies previously undertaken (Carson et al., 2011; Turra et al., 2014). Changes to the incubation environment for eggs could result as microplastics exhibit different physical properties to natural sediments, high abundances could potentially impact nesting success and skew hatchling sex ratios. Carson et al. (2011), used experimental sediment cores to show that higher microplastic abundance increased the permeability and decreased the temperature of sediment. However plastic values in their experimental cores (15.9-29.4\% by weight) producing significant effects were very much higher than levels found in this study. Marine turtle eggs rely on the uptake of water during development, therefore increased permeability from high microplastic abundances has the potential to reduce nesting success through desiccation. Furthermore other studies argue that temperatures would increase with the presence of plastic (especially with dark pigments) as they have a higher specific heat capacity than sand (Andrady, 2011; Beckwith and Fuentes, 2018). Further experimental studies are clearly needed to evaluate the impact of plastic presence in the sand column on critical parameters such as temperature and permeability. Potential study ideas could include experimental "nests" that have been spiked with environmentally relevant plastic concentrations.

\subsection{Among beach variation}

Microplastic abundance varied among sampled beaches with significantly more microplastic was found upon the north coast compared to those of the west or east coast; the influence of current and wind patterns moving of particles around coastline (van Sebille et al., 2015). The Levantine Basin, in which Cyprus is situated, has very little interaction with the rest of the Mediterranean (Hecht et al., 1988). Plastic that enters the basin from surrounding countries (Egypt, Israel, Lebanon, Syria, and Turkey, Cyprus) is also washed up on the beaches of those countries (Mansui et al., 2015; Zambianchi et al., 2017). Hydrodynamic (current) influences were clearly demonstrated within the particle drifter models illustrating to the anticlockwise currents of the Levantine basin. It should be noted, however, the modelled source locations achieved from the model may not be the primary origin of the plastic debris but may be interim locations as plastic moves around the region via offshore accumulation zones. For instance plastic accumulates in the Shikmona anticyclone gyre (SMA), off the SE coast of Cyprus (Alhammoud et al., 2005; Cózar et al., 2015; Zambianchi et al., 2017). This plastic is then caught in the strong north-easterly current and carried up the east coast of Cyprus where it is then propelled westward before being deposited on the north coast (Alhammoud et al., 2005).

\subsection{Variance among plastic categories}

Microplastics sampled varied considerably in abundance between plastic categories (IND, FOAM, FRAG, SHE and THR). Fragments of harder plastics (FRAG) and industrial pellets (IND) making up the majority of the microplastic particles. These differences in migration, breakdown and deposition of different microplastic types may be explained by the re-suspension of sediments; the nature of fragments and rounded pellets behaving in a different way to films, flakes and fibres (Chubarenko and Stepanova, 2017). Indeed modelling of microplastics in the marine environment has revealed that foamed plastics travel fastest over surface water and films and fibres typically sink due to higher rates of bio-fouling than fragments or spheres which could explain their lack of abundance upon beaches (Chubarenko et al., 2016).

\subsection{Call for standardisation}

To better understand the distribution of anthropogenic waste globally, comparative studies are important however this requires standardisation within the field. For example macroplastic and beach litter standards recommendations have been developed by the TG Marine Litter working group, whose guidance covers methodologies and the harmonisation of protocols (Hanke, 2016). They have also refined tool kits for microlitter sampling in intertidal and subtidal sediments, working towards standard methods to sample shorelines, sea 


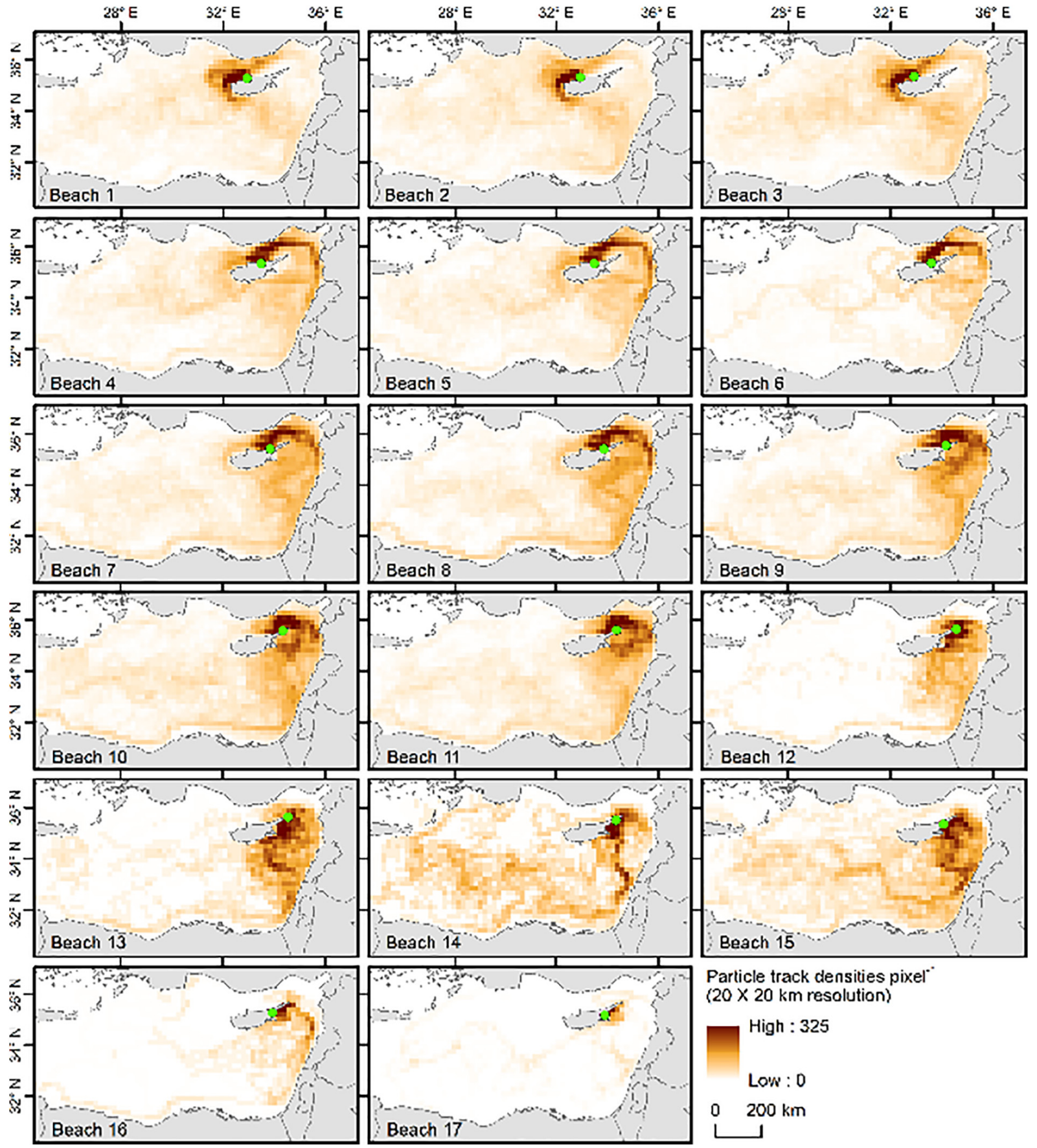

Fig. 4. Particle trajectories (mapped by receiving beach; $n=17$ ) rasterised to a $20 \times 20 \mathrm{~km}$ grid resolution. Tracks per grid square are counted. To enable 'at sea' trajectories to be clearly displayed data within $5 \mathrm{~km}$ of the coast have been removed.

surface and seabed (MSFD GES Technical Subgroup on Marine Litter, 2011). Current methodologies specifically for microplastic sampling still need a number of clarifications to achieve standards. Of priority requirement is a clear definition of 'microplastic'. Whilst a majority of studies take the definition from Andrady (2011) microplastics are particles $<5 \mathrm{~mm}$ in size, some modern studies use the upper boundary of $1 \mathrm{~mm}$, more closely linked to the definition of 'micro' (Browne et al., 2007; Costa et al., 2010; Van Cauwenberghe et al., 2015). Using an upper limit of $1 \mathrm{~mm}$ fails to account for industrial pellets (IND) which have a mean size of 3-4 mm (van Franeker et al., 2011). These plastic particles are too small to fit into other larger plastic sampling, which usually cuts off at a bottle top size of ca. $20 \mathrm{~mm}$ (OSPAR, 2010). As pellets remain significant in both abundance and ingestion, a practical proposal comes as the reclassification of microplastic into 'large microplastic', $1-5 \mathrm{~mm}$ and 'small microplastics', $<1 \mathrm{~mm}$ (Van Cauwenberghe et al., 2015). This would account for both the importance of industrial and finer microscopic fibre filaments (Claessens et al., 2011; Turra et al., 2014). It would allow further neatening of the division between sampling techniques. 'Large microplastic' sampling following more accessible protocols, of sieving and categorisation by eye, as in this study. 'Small microplastics' adopting the refined techniques of particle floatation and microscopic identification (Hidalgo-Ruz et al., 2012).

Secondly we call for standardisation of units in sampling protocols. We noted at least seven different units used within beach sampling papers: particles $\mathrm{m}^{-2}$, particles $\mathrm{m}^{-3}$, particles $\mathrm{g}^{-1}, \mathrm{~g} \mathrm{~m}^{-2}, \mathrm{~g} \mathrm{~m}^{-3}, \mathrm{~g} \mathrm{~g}^{-1}$ 


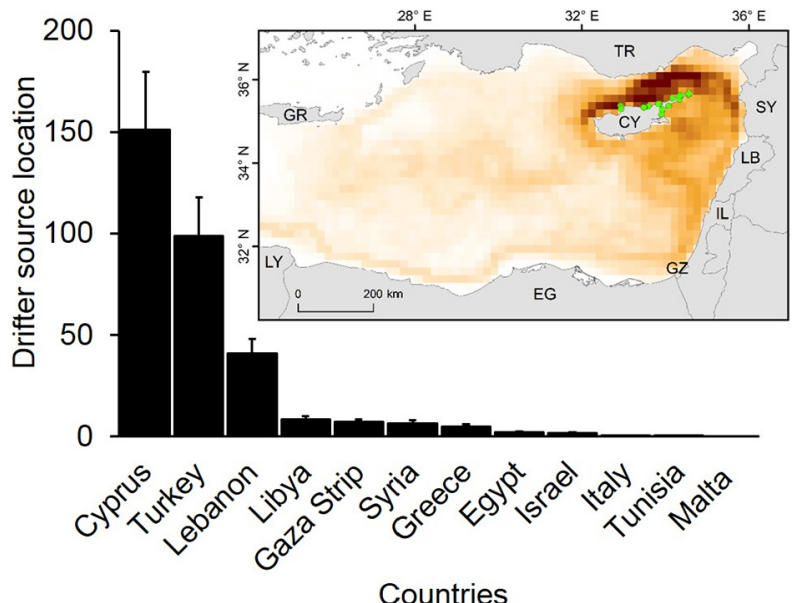

Fig. 5. Drifter source locations (mean \pm s.e.) by country for monitored beaches $(n=17)$. Countries are identified using their 2 digit sovereign state ISO code as follows: Greece (GR), Turkey (TR), Cyprus (CY), Syria (SY), Lebanon (LB), Israel (IL), Gaza Strip (GZ), Egypt (EG) and Libya (LY).

and $\%$ of plastic by weight (Hidalgo-Ruz et al., 2012). We propose reporting data in particles $\mathrm{m}^{-3}$ and $\mathrm{g} \mathrm{m}^{-3}$ for specific area, depth and volumes of sand. Additionally when considering standardisation it is also important to study the chemical characterisation of microplastics removed from beach sediments. Although outside the scope of this study it is becoming evident that obtaining the polymer make-up either by FT-IR or Raman Spectroscopy is highly beneficial for assessment of beach contamination and to understand potential impact (Jung et al., 2018), therefore standard methodologies should include this in their design.

\section{Conclusion}

The turtle nesting beaches of Cyprus are exposed to the highest published microplastic abundances within the Mediterranean, second globally only to Hong Kong, China. The majority of microplastic found in our study originated from industrial spills, followed by fragments from the breakdown of larger plastic pieces. Standardised methodology for sampling microplastic in beach sediment will allow for more effective global comparisons and understanding the effects of this novel pollutant, a research priority for the taxon (Rees et al., 2016). This study highlights that, within the eastern Mediterranean, threats to turtle nesting ecology from microplastic; induced desiccation, toxicology and changes to hatchling sex ratios are possible in the future. Experimental studies of nest environments under variable and experimentally controlled microplastic density are clearly mandated.

\section{Acknowledgements}

The authors would like to thank all the volunteers who assisted with fieldwork as part of the Marine Turtle Conservation Project, a collaboration between the Marine Turtle Research Group, The Society for the Protection of Turtles (SPOT) and the North Cyprus Department of Environmental Protection. We thank the latter department for their continued permission and support. Field work in Cyprus is supported British High Commission in Cyprus, British Residents Society of North Cyprus, Erwin Warth Foundation, Kuzey Kıbrıs Turkcell, Karsiyaka Turtle Watch Turtle Watch, MAVA Foundation, Peoples Trust for Endangered Species, Tony and Angela Wadsworth and the English School of Kyrenia, United States Agency for International Development, Turkish Cypriot Presidency. EMD receives generous support from Roger de Freitas, the Sea Life Trust and the University of Exeter. BJG, KM and ACB receive support from the Darwin Initiative (23-011 and 23-012).
EvS has received funding from the European Research Council (ERC) under the European Union's Horizon 2020 research and innovation programme (grant agreement No 715386). Field work in Cyprus has been supported by the MAVA foundation, and Kuzey Kibris Turkcell. The manuscript was improved as a result of the Editor and three anonymous referees.

\section{Appendix A. Supplementary data}

Supplementary data to this article can be found online at https:// doi.org/10.1016/j.marpolbul.2018.09.019.

\section{References}

Ackerman, R.A., 2002. The nest environment and the embryonic development of sea turtles. In: Lutz, P.L., Musick, J.A., Wyneken, J. (Eds.), The Biology of Sea Turtles I. CRC Press, pp. 83-106.

Alhammoud, B., Béranger, K., Mortier, L., Crépon, M., Dekeyser, I., 2005. Surface circulation of the Levantine Basin: comparison of model results with observations. Prog. Oceanogr. 66, 299-320.

Alomar, C., Estarellas, F., Deudero, S., 2016. Microplastics in the Mediterranean sea: deposition in coastal shallow sediments, spatial variation and preferential grain size. Mar. Environ. Res. 115, 1-10.

Andrady, A.L., 2011. Microplastics in the marine environment. Mar. Pollut. Bull. 62, 1596-1605.

Barnes, D.K. a, Galgani, F., Thompson, R.C., Barlaz, M., 2009. Accumulation and fragmentation of plastic debris in global environments. Philos. Trans. R. Soc. London. Ser. B 364, 1985-1998.

Beckwith, V.K., Fuentes, M.M.P.B., 2018. Microplastic at nesting grounds used by the northern Gulf of Mexico loggerhead recovery unit. Mar. Pollut. Bull. 131, 32-37.

Broderick, A.C., Godley, B.J., 1996. Population and Nesting Ecology of the Green Turtle, Chelonia mydas, and the Loggerhead Turtle, Caretta caretta, in Northern Cyprus.

Broderick, A.C., Glen, F., Godley, B.J., Hays, G.C., 2002. Estimating the number of green and loggerhead turtles nesting annually in the Mediterranean. Oryx 36, 227-235.

Browne, M.A., Galloway, T., Thompson, R., 2007. Microplastic-an emerging contaminant of potential concern? Integr. Environ. Assess. Manag. 3, 559-561.

Carson, H.S., Colbert, S.L., Kaylor, M.J., McDermid, K.J., 2011. Small plastic debris changes water movement and heat transfer through beach sediments. Mar. Pollut. Bull. 62, 1708-1713.

Chubarenko, I., Stepanova, N., 2017. Microplastics in sea coastal zone: lessons learned from the Baltic amber. Environ. Pollut. 224, 243-254.

Chubarenko, I., Bagaev, A., Zobkov, M., Esiukova, E., 2016. On some physical and dynamical properties of microplastic particles in marine environment. Mar. Pollut. Bull. 108, 105-112.

Claessens, M., De Meester, S., Van Landuyt, L., De Clerck, K., Janssen, C.R., 2011. Occurrence and distribution of microplastics in marine sediments along the Belgian coast. Mar. Pollut. Bull. 62, 2199-2204.

Clunies-Ross, P., Smith, G., Gordon, K., Gaw, S., 2016. Synthetic shorelines in New Zealand? Quantification and characterisation of microplastic pollution on Canterbury's coastlines. New Zeal. J. Mar. Freshw. Res. 50, 317-325.

Cole, M., Lindeque, P., Fileman, E., Halsband, C., Goodhead, R., Moger, J., et al., 2013. Microplastic ingestion by zooplankton. Environ. Sci. Technol. 47, 6646-6655.

Coll, M., Piroddi, C., Steenbeek, J., Kaschner, K., Ben Rais Lasram, F., Aguzzi, J., et al., 2010. The biodiversity of the Mediterranean Sea: estimates, patterns, and threats. PLoS One e11842, 5.

Cooper, D.A., Corcoran, P.L., 2010. Effects of mechanical and chemical processes on the degradation of plastic beach debris on the island of Kauai, Hawaii. Mar. Pollut. Bull. 60, 650-654.

Costa, M.F., Ivar do Sul, J.a., Silva-Cavalcanti, J.S., Araújo, M.C.B., Spengler, A. Tourinho, P.S., 2010. On the importance of size of plastic fragments and pellets on the strandline: a snapshot of a Brazilian beach. Environ. Monit. Assess. 168, 299-304.

Cózar, A., Echevarría, F., González-Gordillo, J.I., Irigoien, X., Ubeda, B., Hernández-León, S., et al., 2014. Plastic debris in the open ocean. Proc. Natl. Acad. Sci. U. S. A. 111, 17-19.

Cózar, A., Sanz-Martín, M., Martí, E., González-Gordillo, J.I., Ubeda, B., Gálvez, J.Á., et al., 2015. Plastic accumulation in the Mediterranean Sea. PLoS One 10, e0121762.

Cummings, J.A., Smedstad, O.M., 2013. Variational Data Assimilation for the Global Ocean. In: Data Assimilation for Atmospheric, Oceanic and Hydrologic Applications (Vol. II). Springer Berlin Heidelberg, Berlin, Heidelberg, pp. 303-343.

Derraik, J.G., 2002. The pollution of the marine environment by plastic debris: a review. Mar. Pollut. Bull. 44, 842-852.

Duncan, E., Botterell, Z., Broderick, A., Galloway, T., Lindeque, P., Nuno, A., et al., 2017. A global review of marine turtle entanglement in anthropogenic debris: a baseline for further action. Endanger. Species Res. 34, 431-448.

Europe Plastics, 2016. Plastics-The Facts 2016 an Analysis of European Plastics Production, Demand and Waste Data. Plastics Europe.

Fok, L., Cheung, P.K., Tang, G., Li, W.C., 2017. Size distribution of stranded small plastic debris on the coast of Guangdong, South China. Environ. Pollut. 220, 407-412.

Fossi, M.C., Panti, C., Guerranti, C., Coppola, D., Giannetti, M., Marsili, L., et al., 2012. Are baleen whales exposed to the threat of microplastics? A case study of the Mediterranean fin whale (Balaenoptera physalus). Mar. Pollut. Bull. 64, 2374-2379. 
Gago, J., Carretero, O., Filgueiras, A.V., Viñas, L., 2018. Synthetic microfibers in the marine environment: a review on their occurrence in seawater and sediments. Mar. Pollut. Bull. 127, 365-376.

Gall, S.C., Thompson, R.C., 2015. The impact of debris on marine life. Mar. Pollut. Bull. 92, 170-179.

Hanke, G., 2016. Marine Beach Litter in Europe - Top Items.

Hays, G.C., Mazaris, A.D., Schofield, G., Laloë, J.-O., 2017. Population viability at extreme sex-ratio skews produced by temperature-dependent sex determination. Proc. R. Soc. B Biol. Sci. 284, 20162576.

Hecht, A., Pinardi, N., Robinson, A.R., Hecht, A., Pinardi, N., Robinson, A.R., 1988. Currents, water masses, eddies and jets in the Mediterranean Levantine Basin. J. Phys. Oceanogr. 18, 1320-1353.

Heo, N.W., Hong, S.H., Han, G.M., Hong, S., Lee, J., Song, Y.K., et al., 2013. Distribution of small plastic debris in cross-section and high strandline on Heungnam beach, South Korea. Ocean Sci. J. 48, 225-233.

Hidalgo-Ruz, V., Gutow, L., Thompson, R.C., Thiel, M., 2012. Microplastics in the marine environment: a review of the methods used for identification and quantification. Environ. Sci. Technol. 46, 3060-3075.

Hopewell, J., Dvorak, R., Kosior, E., 2009. Plastics recycling: challenges and opportunities. Philos. Trans. R. Soc. Lond. Ser. B Biol. Sci. 364, 2115-2126.

Horne, C.R., Fuller, W.J., Godley, B.J., Rhodes, K.A., Snape, R., Stokes, K.L., et al., 2014. The effect of thermal variance on the phenotype of marine turtle offspring. Physiol. Biochem. Zool. 87, 796-804.

Ivar Do Sul, J.A., Costa, M.F., 2014. The present and future of microplastic pollution in the marine environment. Environ. Pollut. 185, 352-364.

Jambeck, J.R., Geyer, R., Wilcox, C., Siegler, T.R., Perryman, M., Andrady, a., et al., 2015. Plastic waste inputs from land into the ocean. Science 80 (347), 768-771.

Jung, M.R., Horgen, F.D., Orski, S.V., Rodriguez, V., Beers, K.L., Balazs, G.H., et al., 2018. Validation of ATR FT-IR to identify polymers of plastic marine debris, including those ingested by marine organisms. Mar. Pollut. Bull. 127, 704-716.

Kaberi, H., Tsangaris, C., Zeri, C., Mousdis, G., Papadopoulos, A., Streftaris, N., 2013. Microplastics along the shoreline of a Greek island (Kea isl., Aegean Sea): types and densities in relation to beach orientation, characteristics and proximity to sources. In: Proceedings of the Fourth International Conference on Environmental Management, Engineering, Planning and Economics (CEMEPE 2013) and SECOTOX Conference, June 24-28, 2013, Mykonos island, Greece. Grafima Publ.

Kasparek, M., Godley, B.J., Broderick, A.C., 2001. Nesting of the green turtle, Chelonia mydas, in the Mediterranean: a review of status and conservation needs. Zool. Middle East 45-74.

Laist, D.W., 1987. Overview of the Biological Effects of Lost and Discarded Plastic Debris in the Marine Environment, 18.

Lange, M., van Sebille, E., 2017. Parcels v0.9: prototyping a Lagrangian ocean analysis framework for the petascale age. Geosci. Model Dev. 10, 4175-4186.

Mansui, J., Molcard, A., Ourmières, Y., 2015. Modelling the transport and accumulation of floating marine debris in the Mediterranean basin. Mar. Pollut. Bull. 91, 249-257.

McGehee, M.A., 1990. Effects of moisture on eggs and hatchlings of Loggerhead Sea turtles (Caretta caretta). Herpetologica 46, 251-258.

Moore, C.J., 2008. Synthetic polymers in the marine environment: a rapidly increasing, long-term threat. Environ. Res. 108, 131-139.

Moreira, F.T., Balthazar-Silva, D., Barbosa, L., Turra, A., 2016. Revealing accumulation zones of plastic pellets in sandy beaches. Environ. Pollut. 218, 313-321.

Morét-Ferguson, S., Law, K.L., Proskurowski, G., Murphy, E.K., Peacock, E.E., Reddy, C.M., 2010. The size, mass, and composition of plastic debris in the western North Atlantic Ocean. Mar. Pollut. Bull. 60, 1873-1878.

MSFD GES Technical Subgroup on Marine Litter, 2011. Marine Litter Technical Recommendations for the Implementation of MSFD Requirements.

Nelms, S.E., Duncan, E.M., Broderick, A.C., Galloway, T.S., Godfrey, M.H., Hamann, M., et al., 2016. Plastic and marine turtles: a review and call for research. ICES J. Mar. Sci. $73,165-181$.
Nelms, S., Coombes, C., Foster, L., Galloway, T., Godley, B., Lindeque, P., et al., 2017 Marine anthropogenic litter on British beaches: a 10-year nationwide assessment using citizen science data. Sci. Total Environ. 579, 1399-1409.

OSPAR, 2010. Edition 1.0 Guideline for Monitoring Marine Litter on the Beaches in the OSPAR Maritime Area.

Poeta, G., Battisti, C., Acosta, A.T.R., 2014. Marine litter in Mediterranean sandy littorals: spatial distribution patterns along central Italy coastal dunes. Mar. Pollut. Bull. 89, $168-173$.

Rees, A.F., Alfaro-Shigueto, J., R Barata, P.C., Bjorndal, K.A., Bolten, A.B., Bourjea, J., et al., 2016. Are we working towards global research priorities for management and conservation of sea turtles? Endanger. Species Res. 31, 337-382.

Ryan, P.G., Connell, A.D., Gardner, B.D., 1988. Marine pollution bulletin plastic ingestion and PCBs in seabirds: is there a relationship? Mar. Pollut. Bull. 19, 174-176.

Stokes, K.L., Broderick, A.C., Canbolat, A.F., Candan, O., Fuller, W.J., Glen, F., et al., 2015. Migratory corridors and foraging hotspots: critical habitats identified for Mediterranean green turtles. Divers. Distrib. 665-674.

Storelli, M.M., Zizzo, N., 2014. Occurrence of organochlorine contaminants (PCBs, PCDDs and PCDFs) and pathologic findings in loggerhead sea turtles, Caretta caretta, from the Adriatic Sea (Mediterranean Sea). Sci. Total Environ. 472, 855-861.

Tanaka, K., Takada, H., Yamashita, R., Mizukawa, K., Fukuwaka, M.-A., Watanuki, Y., 2012. Accumulation of plastic-derived chemicals in tissues of seabirds ingesting marine plastics. Mar. Pollut. Bull. 69, 219-222.

Thom, B.G., Hall, W., 1991. Behaviour of beach profiles during accretion and erosion dominated periods. Earth Surf. Process. Landf. 16, 113-127.

Tsang, Y.Y., Mak, C.W., Liebich, C., Lam, S.W., Sze, E.T.-P., Chan, K.M., 2017. Microplastic pollution in the marine waters and sediments of Hong Kong. Mar. Pollut. Bull. 115, 20-28.

Turner, A., Holmes, L., 2011. Occurrence, distribution and characteristics of beached plastic production pellets on the island of Malta (central Mediterranean). Mar. Pollut. Bull. 62, 377-381.

Turra, A., Manzano, A.B., Dias, R.J.S., Mahiques, M.M., Barbosa, L., Balthazar-Silva, D., et al., 2014. Three-dimensional distribution of plastic pellets in sandy beaches: shifting paradigms. Sci. Rep. 4, 4435.

Van Cauwenberghe, L., Devriese, L., Galgani, F., Robbens, J., Janssen, C.R., 2015. Microplastics in sediments: a review of techniques, occurrence and effects. Mar. Environ. Res. 2009.

van Franeker, J.A., Blaize, C., Danielsen, J., Fairclough, K., Gollan, J., Guse, N., et al. 2011. Monitoring plastic ingestion by the northern fulmar Fulmarus glacialis in the North Sea. Environ. Pollut. 159, 2609-2615.

van Sebille, E., Wilcox, C., Lebreton, L., Maximenko, N., Hardesty, B.D., van Franeker, J.A., et al., 2015. A global inventory of small floating plastic debris. Environ. Res. Lett. 10, 124006 .

van Sebille, E., Griffies, S.M., Abernathey, R., Adams, T.P., Berloff, P., Biastoch, A., et al., 2018. Lagrangian ocean analysis: fundamentals and practices. Ocean Model 121, 49-75.

Vegter, A., Barletta, M., Beck, C., Borrero, J., Burton, H., Campbell, M., et al., 2014. Global research priorities to mitigate plastic pollution impacts on marine wildlife. Endanger. Species Res. 25, 225-247.

Warner, D.A., 2014. Fitness consequences of maternal and embryonic responses to environmental variation: using reptiles as models for studies of developmental plasticity. Integr. Comp. Biol. 54, 757-773.

Yu, X., Peng, J., Wang, J., Wang, K., Bao, S., 2016. Occurrence of microplastics in the beach sand of the Chinese inner sea: the Bohai Sea. Environ. Pollut. 214, 722-730.

Zambianchi, E., Trani, M., Falco, P., 2017. Lagrangian transport of marine litter in the Mediterranean Sea. Front. Environ. Sci. 5, 5.

Zhang, K., Su, J., Xiong, X., Wu, X., Wu, C., Liu, J., 2016. Microplastic pollution of lakeshore sediments from remote lakes in Tibet plateau, China. Environ. Pollut. 219, 450-455. 